\title{
Rationale of using different biological therapies in rheumatoid arthritis
}

\author{
Matthias Geyer and Ulf Müller-Ladner*
}

\begin{abstract}
Due to ongoing developments of novel agents in the field of biological pharmacotherapy, there are now more arrows available in clinicians' quivers for the treatment of rheumatic conditions. As a consequence, however, clear treatment strategies have to be defined in order to guarantee a qualitatively high and individually stage-adapted, state-of-the-art regimen for affected patients. This review summarizes recent evidence regarding the rationale of using different biological therapies to treat rheumatoid arthritis, the most common inflammatory joint disorder after activated osteoarthritis, and draws an actual picture of a possible standardized therapeutic algorithm without claiming exclusive appropriateness.
\end{abstract}

\section{Introduction}

The cure of diseases or at least an abatement of symptoms are the core aims of therapeutic medicine, and we might soon witness the transition from today's abatement to tomorrow's cure with regard to the quality of disease remission in the field of rheumatic conditions, with rheumatoid arthritis (RA) as one of the most frequent entities. At present, achieving complete remission is the ultimate aim, at least for patients with recently diagnosed, early RA. The reduction of clinical disease activity below a disease activity score of 2.6 when evaluating the 28 relevant joints (DAS28), as well as the exclusion of still remaining clinically silent synovial inflammation, are considered to be the principal goals of current rheumatologic treatment concepts [1]. In cases with longer histories and at later stages of disease, however, the cutoff level for individually acceptable residual disease activity might have to be further defined together with the patient, and on the basis of this, individual

*Correspondence: u.mueller-ladner@kerckhoff-klinik.de

Justus-Liebig-University of Giessen, Department of Rheumatology and Clinical Immunology, Kerckhoff-Klinik, Benekestr. 2-8, D-61231 Bad Nauheim, Germany stage-adapted medication evaluated continuously in close agreement with the patient $[1,2]$.

Past pharmacologic options used to induce remission from RA included chrysotherapy, which became the first established 'gold' standard. In 1928, Jacques Forestier had already started to use gold salts therapeutically in France, assuming an infectious factor in RA, which was in the tradition of Robert Koch's evaluation of gold compounds against pure cultures of Mycobacterium tuberculosis [3]. Gold salts, however, were just one drug amongst a growing number of long-acting, remission-inducing agents showing only slow action in decreasing the inflammatory activity of RA. Owing to this mode of action, they have been termed 'second-line' medication, also known as disease-modifying anti-rheumatic drugs (DMARDs); apart from gold salts, these also include medications such as azathioprine, chloroquine and hydroxychloroquine (HQ), cyclosporin A (CsA), cyclophosphamide, leflunomide (LEF), methotrexate (MTX), and sulfasalazine (SSZ). The mechanisms of action of some of these drugs are still not fully defined, but they are likely to involve an overlap between anti-inflammatory, immunosuppressive and cytotoxic properties. Nonetheless, only DMARDs may significantly slow, stop or even reverse the damage arising from chronic inflammation in cartilage or bone, as shown in an in vitro study on human chondrocytes in alginate cultures [4], for example, as well as in clinical trials implementing radiographic follow-up of patients (see 'Current repertoire, profiles and clinical evidence for biologics in RA' below). However, although DMARDs may slow radiographic progression, data also illustrate that progression can continue despite clinical disease control or remission [5].

First-line non-steroidal anti-inflammatory drugs (NSAIDs) and steroids, in contrast, more rapidly inhibit local inflammatory symptoms but have only little to no long-lasting effects on the systemic aspects of RA, as reflected by increased erythrocyte sedimentation rates or elevated levels of C-reactive protein. Therefore, systemic signs of inflammatory rheumatic conditions that patients may complain of - for example, loss of efficiency, lassitude or weight reduction - are not improved by non-selective cyclooxygenase inhibitors, such as diclofenac, ibuprofen, 
naproxen, piroxicam, meloxicam, indometacin or acemetacin, nor by the selective cyclooxygenase- 2 inhibitors celecoxib or etoricoxib.

Members of the so-called biologics, formally classified as a distinct subgroup within the DMARDs, form part of a specific therapeutic strategy targeting pro-inflammatory key cytokines and cellular functions that have deleterious effects during the course of RA. Current options include not only several agents against TNF- $\alpha$, but also compounds directed against IL- 1 or IL- 6 and modulators of B-cell or T-cell activity. Since biologics are known for their potential to abolish disease progression and persistent residual activity, it is not unreasonable to alternatively call them disease-controlling anti-rheumatic drugs [6].

Most importantly, the ongoing developments in this field require a thorough knowledge of the properties and effects the currently available repertoire of target-specific biological agents may display in the treatment of RA. This review refers to the recent clinical evidence for the use of different biological therapies in RA, discusses their efficacy and safety profiles and tries to define in which situations their administration may prove beneficial for the patient.

\section{General considerations when designing a patient-oriented treatment plan}

Many factors contribute to the specific treatment strategy used in RA. Data derived from controlled clinical trials form the prerequisite on which the status of approval, the approved indications and also the availability of a certain substance may prompt the treating physician to consider it within his or her repertoire based on his or her available knowledge and experience in the diagnosis, treatment and assessment of RA. Since biological substances show not negligible profiles of possible side effects and may sometimes even cause serious complications, the reasonable use of biological agents also requires especial awareness of their respective efficacies versus toxicities. All individual patients or their representatives should therefore be provided with any information needed such that they are fully enabled to estimate the risk-benefit analysis themselves, especially as patients differ in their risk for and expression of these side effects as well as in the clinical presentation of their disease. It is of critical importance to consider individual comorbidities regarding the cardiovascular system, pulmonary, hepatic and nephrologic status, hematooncologic alterations as well as neurological conditions and individual risk for infections. The duration of the existing RA disease course, previous therapies, and the duration until a medication takes effect, its antiinflammatory properties, its efficacy on the deferment of erosions, the mode of application, and interactions with co-medication form central elements of which the treating physician has to be aware. Age, gender, desire for children as well as individual employment situation further contribute to the decision for or against a certain medication [1].

The actual state of the disease should be recorded before initiating a regimen; it is important to evaluate tender and swollen joint counts, general disease activity as considered by both physician and patient, the intensity of pain as assessed by visual analogue scales, the duration of morning stiffness, functional disability assessed by suitable questionnaires, as well as the erythrocyte sedimentation rate and the level of C-reactive protein [7]. Predictors for the erosive character of the individual disease course may not only be given by the existing duration of disease, but also by the number of affected joints, the involvement of carpi, metacarpo-phalangeal, metatarso-phalangeal and proximal interphalangeal joints, the presence of anti-cyclic citrullin peptide antibodies and rheumatoid factors, the ultrasound-measured intensity of synovialitis, the detection of bone marrow edema by magnetic resonance imaging, and early erosive events detected with conventional X-ray analysis [7].

Several validated measures can be employed to evaluate the response to treatment while continuously following patients over time. These may include the Disease Activity Score (DAS), the Simplified Disease Activity Index (SDAI), the Clinical Disease Activity Index (CDAI), the Health Assessment Questionnaire Disability Index (HAQ-DI), various visual analogue scales, Likert scales of global response or pain as measured by the patient or the physician, as well as other validated instruments of pain measurement for individual patient care. The number of tender and swollen joints and laboratory data should also be re-evaluated to obtain a complete picture of the therapeutic suitability and a sense of the need for possibly relevant modifications according to the individual patient's status [8].

\section{Current repertoire, profiles and clinical evidence for biologics in rheumatoid arthritis} TNF-blocking agents

At present, five TNF-blocking agents are available and approved for use in RA: etanercept, adalimumab, infliximab, certolizumab and golimumab. Whereas etanercept, adalimumab and certolizumab are approved as monotherapy for RA, infliximab and golimumab are only approved in combination with MTX. As monotherapy, TNF-blocking agents have proven efficacy in patients with limited response to MTX [9]. However, combination of a TNF blocker with MTX yields better results than using either substance alone [10,11]. Moreover, preliminary data derived from comparative studies show that using MTX together with a TNF inhibitor might be 
superior to combinations of traditional DMARDs [12]. Nonetheless, TNF inhibitors may also be used in conjunction with DMARDs other than MTX - for example, with leflunomide or sulfasalazine - according to individual patients' needs.

Although TNF inhibitors exhibit differences in their composition and pharmacokinetic and pharmacodynamic properties, no evidence suggests that any of these agents should be used prior to any other or that one TNF blocking agent is more effective than any other in RA. Administering TNF-blocking agents up to the maximum approved dose for RA may evoke a response within 2 to 4 weeks in some patients, but a significant amelioration of disease should be seen within 12 to 24 weeks, leading to a documentable improvement in clinical and laboratory parameters. In this case, the treatment should be continued according to the physical and patientoriented measures.

Increasing the dose or reducing the intervals of administration may have additional benefit. When achieving remission or dealing with a low disease activity, an ongoing therapeutic effect may be sustained successfully despite a lowering of the dose [13]. In contrast, when failing to evoke any response, continued administration of a TNF inhibitor should be appraised critically. A loss of response to TNF blockers can occur, but this does not necessarily preclude a response to another substance, since time and again patients have been switched successfully from one compound to another [14]. However, it is possible that patients who fail to respond to a first TNF inhibitor could also fail to respond to a second one [8]. The same is true for tolerance of the medication, although patients may show a response to it. Even when not displaying a clinical response, TNFblocking agents were shown to slow or even to stop radiographic progression of RA [15]. Of note, improved combined clinical and radiological outcomes can be achieved using a combination of both a TNF blocker and a traditional DMARD.

Considering the safety profile of TNF inhibitors in general, treating physicians should not only be aware of possible complications linked to infections, malignancies, and the cardiovascular and pulmonary systems, but should also be familiar with haematological, neurological and hepatic symptoms as well as with the risk for autoimmune-like reactions and injection site reactions or adverse events during pregnancy.

Regarding infections, tuberculosis (TBC) represents a major risk when being treated with TNF blocking agents. This implies both an increased susceptibility to TBC and the reactivation of latent TBC. Administration of corticoids also increases the risk. To date, no studies have made head-to-head comparisons of TNF inhibitors so no instructive data are available for the incidence of reactivation of latent TBC. However, clinical presentation of active cases may be atypical during administration of TNF-blocking agents [16]. Furthermore, not all instances of mycobacterial infection may be due to M. tuberculosis, as Mycobacterium avium and others also account for reactivated disease [17]. Nevertheless, it is recommended to screen patients for latent TBC before initiating a therapeutic TNF blockade, as well as to evaluate any history of a potential prior exposure to mycobacteria [18]. It is appropriate to use tests such as the tuberculin skin test or assays measuring interferon- $\gamma$ release, which have higher specificity for detecting latent $T B C$ and could thus prevent false positive results due to a bacillus Calmette-Guérin (BCG) vaccination in the past [19]. There is currently no consensus about when to start TNF blockade after initiating treatment for latent TBC. Similarly, care has to be taken in the context of nontuberculous mycobacteria [20], listeriosis [21], coccidiomycosis [22] and histoplasmosis [23]. Accordingly, medication with TNF-blocking agents should not be performed in the context of serious or opportunistic infections or of septic complications, such as septic arthritis, infected prostheses, acute abscesses or osteomyelitis, as some studies indicated that certain sites may show serious infections more frequently, including the skin, soft tissues and joints [24]. The incidence of serious infections is even higher when using a TNF-blocking agent in combination with anakinra (ANR) or abatacept $(\mathrm{ABC})[25,26]$. Therefore, the combination of two biological agents still remains a therapeutic challenge.

Care has to be taken in patients with chronic viral hepatitis $\mathrm{B}$ and $\mathrm{C}$ when using TNF-blocking agents. When hepatitis B infection is known of before treatment, use of TNF blockers should be considered only in exceptional cases after adequate treatment of the virus [27]. If the infection is diagnosed during the use of a TNF inhibitor, prophylactic antiviral therapy could be considered. In contrast, data for hepatitis $\mathrm{C}$ did not show any increased incidence of toxicity during TNF inhibitor treatment $[27,28]$.

With regard to vaccination, TNF-blocking agents usually do not have any adverse effect on the synthesis of protective antibodies in the case of influenza vaccines despite a slight decrease in the titre of response, especially when used in combination with MTX [29]. Nevertheless, application of live attenuated vaccines is not recommended.

No significant evidence is given for the development of solid malignancies during anti-TNF therapy, as analyses reporting a higher rate of solid tumours are counterbalanced by studies that do not support this hypothesis in patients undergoing TNF blockade in comparison to matched controls. In general, however, the incidence of lymphoma was been found to be higher in chronic 
inflammatory diseases, including RA [30]. Thus, increased risk for malignant lymphomas, especially nonHodgkin's lymphoma, in RA patients in contrast to the general population has been reported [31]. Therefore, the occurrence of malignancies should be surveyed in RA patients being treated with TNF blockers.

Results on the incidence of heart failure in patients with RA receiving TNF inhibitors are conflicting [32]. Also, TNF inhibitor treatment has been associated with a surprising effect on lipid metabolism [33] and rare cases of interstitial lung disease [34]. Additionally, central and peripheral demyelinating syndromes may occur [35]. Although autoantibody formation, such as antinuclear antibodies, is not uncommon with TNF blockade, associated clinical conditions are rare, but might be seen as antiphospholipid and lupus-like syndromes [36,37]. Injection-site reactions due to TNF administration occur with mild to moderate intensity [38]. Safety data for TNF inhibitor treatment during pregnancy are incomplete. Whether anti-TNF therapy should be stopped during pregnancy or whether continued administration is safe and without risk of fetal loss or miscarriages and association with a VACTERL syndrome (vertebral/anal/ cardiac abnormalities, tracheo-esophageal fistulation, esophageal/renal/limb defects) is not clear at present [39].

\section{Rituximab}

Rituximab (RIX) is a chimaeric anti-CD20 monoclonal antibody originally approved for the treatment of CD20+ B-cell non-Hodgkin's lymphoma and chronic lymphocytic leukaemia. For RA, RIX has been approved for the treatment of moderate to severe forms together with MTX in patients with an inadequate reponse to at least one TNF-blocking agent, or when TNF blockade is inappropriate, respectively $[40,41]$. In these patients, RIX is able to inhibit radiographic progression [42]. However, RIX may also be used in conjunction with DMARDs other than MTX or as monotherapy [43].

RIX can be given intravenously as two 1,000 mg infusions 2 weeks apart under support of $100 \mathrm{mg}$ prednisolone equivalent. This remains the labelled dose, although two $500 \mathrm{mg}$ doses have also been evaluated and demonstrated to provide equivalent clinical efficacy [40]. Significant improvements in signs and symptoms of RA have been observed after 8 to 16 weeks [44,45], with better responses in rheumatoid factor-positive and anticyclic citrullin peptide antibody-positive patients and DMARD and TNF non-responders $[41,46]$. Repeated treatment courses each consisting of two infusions given 2 weeks apart are effective in previously responsive patients [47], with each course being given no earlier than 16 weeks after the previous one. Whether retreatment of initial non-responders, possibly representing a different pathogenetic subset of RA, is effective remains to be determined [48].

The most frequent adverse event with RIX is an infusion reaction, but this is more often seen with the first application of each course and is usually less prominent with all subsequent infusions and can be prevented by the adequate use of intravenous corticosteroids.

Before treatment with RIX, patients should be evaluated for a history of hepatitis B infection, since reactivation of hepatitis $B$ was reported in patients who were treated with RIX due to non-Hodgkin's lymphoma but received additional chemotherapy [49].

With regard to infections, not enough data are available to clearly determine the need for TBC screening before initiating RIX treatment. Therefore, the treating physician has to be aware of possible (re-)occurrences of TBC during therapy. In general, RIX is contraindicated in the presence of serious and opportunistic infections. Without these pre-existing infections, a slight increase in infectious events was found during RIX administration at a dose of $2 \times 1,000 \mathrm{mg}$ in comparison to placebo [50].

The detailed role of $B$ cells in RA remains to be elucidated because a more complete depletion of the peripheral $\mathrm{CD}^{2} 0^{+}$subpopulation following treatment with RIX was not consistently predictive for achieving or maintaining a clinical response in RA patients, suggesting that the timing of re-treatment should rather be based on disease activity than repletion of peripheral B cell levels [51]. As a consequence of B-cell depletion, any vaccinations desired by the patient (for example, for preventing influenza and pneumonia) should be given before treatment, although indicated vaccinations during treatment except for with live attenuated ingredients should still be given despite a lowered response [49].

Although no evidence underlines the association of RIX with an increased incidence of solid malignancies in RA, vigilance for this seems appropriate. Neurological complications, such as progressive multifocal leucoencephalopathy, remain a very rare event, but have been reported in cases of RA treated with RIX [52]. The same is true for unclear associations of psoriasis with RIX treatment [53]. Most cases of progressive multifocal leucoencephalopathy, however, were in patients who also had established risk factors for it.

\section{Abatacept}

Abatacept $(A B C)$ is a fusion protein consisting of the extracellular portion of human cytotoxic T-lymphocyte antigen 4 (CTLA-4) and the $\mathrm{F}_{c}$ domain of IgG1. It binds to both CD80 and CD86 on antigen-presenting cells and interrupts the co-stimulatory effect via CD28 on T cells.

It is approved both as monotherapy and in combination with DMARDs for moderate to severe adult RA and polyarticular juvenile idiopathic arthritis. Use of $A B C$ 
should be considered after inadequate response to one or more non-biological DMARDs and a failure of at least one TNF-blocking agent $[54,55]$. Direct switching to $\mathrm{ABC}$ after anti-TNF therapy can be performed without the need for a washout [56].

$\mathrm{ABC}$ is given intravenously at doses of 8 to $10 \mathrm{mg} / \mathrm{kg}$ body weight: $500 \mathrm{mg}$ for patients $<60 \mathrm{~kg}, 750 \mathrm{mg}$ for patients 60 to $100 \mathrm{~kg}$, and 1,000 $\mathrm{mg}$ for patients $>100 \mathrm{~kg}$, at weeks 0,2 and 4 and then every 4 weeks. Some patients begin to respond within 2 to 4 weeks according to American College of Rheumatology criteria, and most individuals respond within 12 to 16 weeks after treatment initiation. Improvement may continue for up to 1 year, and increased inhibition of radiographic progression may occur even in the second year [57]. The efficacy of ABC is similar to that of infliximab $3 \mathrm{mg} / \mathrm{kg}$, but there is a lower number of serious complications [58].

The use of $A B C$ in patients with chronic obstructive pulmonary disease led to more serious lower respiratory tract infections than placebo treatment [8]. The risk for reactivation of latent $\mathrm{TBC}$ or developing new disease during $\mathrm{ABC}$ treatment has not been evaluated. In all phase III trials, patients were still enrolled despite a positive tuberculin skin test and being treated for latent TBC [8]. Combination of ABC with TNF blockers is not recommended due to an elevated risk for serious infections [26,59]. As with TNF blockers, live vaccines should not be given during or up to 3 months after $A B C$ treatment. Evaluation of the risk for increases in neoplasm formation is still to be done.

\section{Anakinra}

Anakinra (ANR) is a recombinant protein identical to the physiologic IL-1 receptor antagonist (IL-1Ra), with the exceptions of having an additional methionine residue and lacking glycosylation. Approved for use in RA, ANR can be applied for active diseases as monotherapy or in combination with MTX at dosages of $100 \mathrm{mg}$ per day subcutaneously after appropriate trials of non-biological DMARDs [60,61]. Of important note, however, addition of ANR to anti-TNF therapy is not recommended due to increased rates of serious adverse events [25,62].

ANR significantly improves signs and symptoms of RA and is able to slow radiographic progression $[60,62]$. Ongoing use of ANR should be re-evaluated after 16 weeks without any improvement. ANR administration should not be considered or continued in patients with serious infections as bacterial infections were more often observed in patients treated with ANR than with those treated with non-biological DMARDs [63]. Injection site reactions comprise the most frequent adverse event, with $71 \%$ of patients receiving ANR versus $28 \%$ receiving placebo experiencing an injection site reaction according to a recent systematic analysis [64]. Since the efficacy demonstrated in trials was modest and lower than for other biological agents, the margin of benefit seems to be smaller $[64,65]$. Thus, the exact position and value of ANR in the therapy of RA have to be further defined by ongoing long-term observational studies.

\section{Tocilizumab}

Tocilizumab (TOZ) is a humanized monoclonal anti-IL-6 receptor antibody. It is administered intravenously in monthly dosages of 4 or $8 \mathrm{mg} / \mathrm{kg}$ body weight and is approved for moderate to severe active RA in combination with MTX or as a monotherapy in incomplete responders to DMARDs or TNF-blocking agents, where it can reduce the signs and symptoms of disease [66,67]. Note that in the US, TOZ does not have a before TNF indication, in contrast to its EU status. The onset of response might occur after just 2 to 4 weeks in some cases, but TOZ might also take effect only after up to 24 weeks.

Infusion site reactions to a serious extent are quite rare. Other specific side effects are increases in fasting plasma lipids, such as total cholesterol, low-density lipoprotein and triglycerides, which may have to be treated with statins [68-70]. There was no significant increase in cardiovascular or cerebrovascular events for at least up to 1.5 years of median follow-up in one study [68]. TOZ should be used with caution in patients with a history of intestinal ulceration or diverticulitis because peritonitides, lower gastrointestinal perforations, fistulae, and intraabdominal abscesses have been documented in trials of 6-months' duration [67]. In addition, there were more cases of transient neutropenia early after infusion in TOZ-treated patients than in controls receiving placebo [69]; thus, blood counts should be monitored regularly.

Although there is no evidence for serious liver affections or failure provoked by TOZ, organ function should also be evaluated at regular intervals due to the frequency of slight and often transient increases in aminotransferases [69]. An association of TOZ treatment with higher frequencies of neoplasm formation has not been proven so far. Moreover, the rate of serious infections did not increase significantly in the studies performed, but similar care as with other biologics might be necessary when administering TOZ in patients with pre-existing serious or opportunistic infections, especially as few data convincingly refer to the management of TBC in this context because no such patients have been included in the studies. Links to viral infections such as with herpes zoster also still have to be confirmed. This is also the case for vaccinations against influenza, which might be safe and effective despite TOZ treatment, although live vaccines should not be given.

In summary, more detailed safety data addressing the infectiological, immunological, neoplastic, cardiovascular 
Table 1. Current repertoire of biological agents for the treatment of rheumatoid arthritis

\begin{tabular}{|c|c|c|}
\hline Biological agent & Dose and mode of application & Approved indications \\
\hline Etanercept $\left(\right.$ Enbrel $\left.^{\circledR}\right)$ & 25 mg s.c. twice weekly, 50 mg s.c. weekly & Monotherapy, combination therapy \\
\hline Adalimumab (Humira $\left.{ }^{\oplus}\right)$ & 40 mg s.c. every 2 weeks & Monotherapy, combination therapy \\
\hline Infliximab (Remicade ${ }^{\circledast}$ ) & $\begin{array}{l}3 \mathrm{mg} / \mathrm{kg} \text { i.v. every } 2 \text { to } 4 \text { weeks, then extending intervals up to } 8 \text { weeks; } \\
\text { maximum dose } 5 \text { to } 7 \mathrm{mg} / \mathrm{kg} \text { every } 4 \text { weeks }\end{array}$ & Only in combination with MTX \\
\hline Certolizumab (Cimzia $\left.{ }^{\oplus}\right)$ & 200 mg s.c. every 2 weeks (after loading dose) & Monotherapy, combination therapy \\
\hline Golimumab (Simponi甲) & 50 mg s.c. monthly & Only in combination with MTX \\
\hline Rituximab (MabThera ${ }^{\circledast}$ ) & $\begin{array}{l}\text { Course of } 2 \times 500 / 1,000 \mathrm{mg} \text { i.v. with an interval of } 2 \text { weeks; several courses } \\
\text { every } 4 \text { to } 8 \text { months possible }\end{array}$ & With or without MTX \\
\hline Abatacept (Orencia $\left.{ }^{\circledast}\right)$ & $\begin{array}{l}8 \text { to } 10 \mathrm{mg} / \mathrm{kg} \text { i.v. }(500 \mathrm{mg}(<60 \mathrm{~kg}), 750 \mathrm{mg}(60 \text { to } 100 \mathrm{~kg}), 1 \mathrm{~g}(>100 \mathrm{~kg})) \\
\text { at weeks } 0,2,4 \text {, then monthly }\end{array}$ & With or without MTX \\
\hline Tocilizumab (RoActemra $\left.{ }^{\circledR}\right)$ & $8 \mathrm{mg} / \mathrm{kg}$ i.v. monthly & Monotherapy, combination therapy \\
\hline Anakinra (Kineret $\left.{ }^{\oplus}\right)$ & 100 mg/day s.c. & With or without MTX \\
\hline
\end{tabular}

I.v., intravenously; MTX = methotrexate; s.c., subcutaneously.

and hepatic implications of TOZ treatment have to be gathered by upcoming extension studies.

Table 1 summarizes the dosages and mode of application of the biologics currently approved for the treatment of RA.

\section{Combining the evidence into possible 'standardized' pharmacologic procedures}

In the context of the safety, efficacy, indications and administration-related profiles of biological agents as well as patient-related treatment criteria that should be considered before and during each treatment regimen, this section suggests a possible, non-dogmatic standardized practical algorithm for a pharmacological treatment strategy in patients with RA. However, despite internationally disposable results of sometimes even longterm observations during clinical studies, national preferences may lead to different procedures. Nonetheless, the following procedure, which is based on what has been discussed so far, might prove suitable in most cases, always keeping in mind patients' individual situations, of course. Figure 1 schematically recapitulates the evidencebased procedure.

Before initiating biological pharmacotherapy in RA, the treating physician may first start with MTX, considered today's gold standard in the initial treatment algorithm. This could be done first by subcutaneous application of $15 \mathrm{mg}$ once a week before oral administration, accompanied by substitution of folic acid. Discontinuation prior to any surgical need is not necessary. As higher doses of corticosteroids are not required with MTX, it may be accompanied by low doses of prednisolone or equivalent. Following re-evaluation after a 6-week period, it is possible to increase the amount of MTX up to $30 \mathrm{mg}$. Another 6 weeks later, that is, 3 months after initiating therapy, leflunomide might be added to MTX or be given alone. Alternatively, sulfasalazine and hydroxychloroquine or cyclosporin A might be added to MTX. After another 3 months, biologics can be used, usually beginning with TNF antagonists. Whereas infliximab and golimumab are to be given in combination with MTX, however, adalimumab, etanercept and certolizumab may replace MTX and could also be administered as monotherapy. A combination of leflunomide with an anti-TNF agent is also possible. If this strategy fails, a second TNF blocker could be tried, although it is uncertain if this might be superior and lead to a significant response. Instead, it would also be suitable to switch from TNF blockers and use TOZ, RIX or ABC. TOZ is also approved to be given without prior trials of anti-TNF agents directly after MTX application. RIX may be given retentively in patients who are rheumatoid factor-negative but shows advantages in rheumatoid factor-positive patients. Switching to another biologic after RIX does not require the repletion of peripheral Bcell levels. Similarly, administration of ABC after antiTNF treatment can be started without waiting for any corresponding washout. $\mathrm{ABC}$ is also licensed for use after failure of RIX. To a lesser extent, ANR might also represent a possible option in individual treatment plans, although its clear value and position within a possible pharmacotherapeutic algorithm of RA require further evidence from clinical observations.

\section{Conclusions}

Owing to the growing number of pharmacological options in treating rheumatic conditions such as RA, it has become more important to keep up to date with the evidence for the use of novel agents and their roles within treatment. When starting to design an individual regimen, one has to be cognizant of the following central elements: data retrieved from a variety of different 


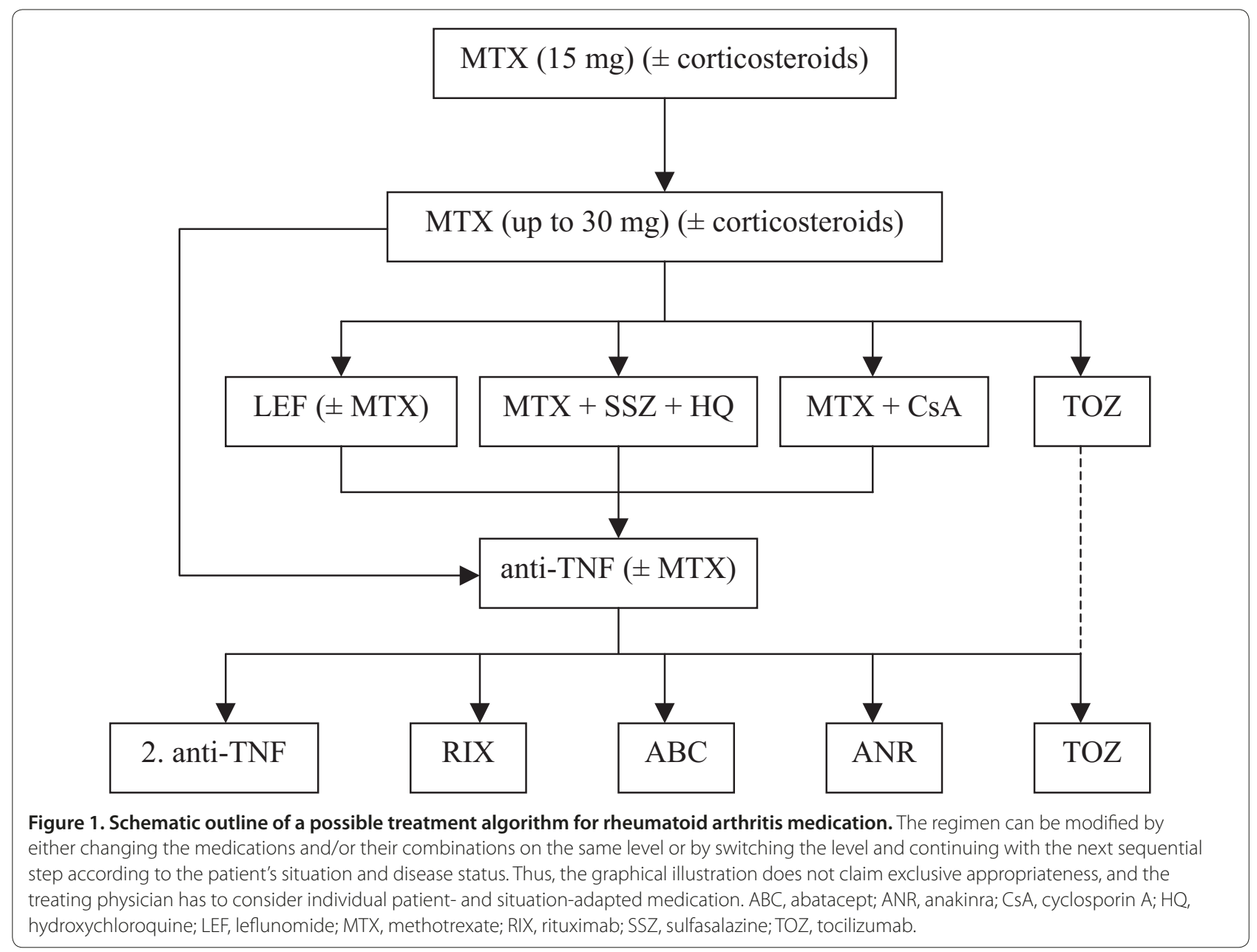

clinical studies; the resulting status of approval; approved indications; and post-marketing surveillance data of newly available biological agents, also reflecting their safety profiles and their possible interactions with other medications and conditions and their side effects in different patient cohorts comprising individuals with different personal circumstances. The elaboration of practical algorithms is intended to help physicians choose suitable drugs for therapy routines and for the general follow-up of patients and the management of disease concomitants. These should therefore implement strategies checking for any complications prior to or during drug administration as well as guidelines for practical limitations associated with, for example, intolerance, comorbidities, surgery, vaccination, pregnancy, travel or work. This might add to further unify and standardize treatment procedures for patients with RA or other rheumatic conditions by reaching even greater consensus, assisting to continuously ameliorate individual therapy adaptation and to provide eventual necessary interventions without any delay in an optimized system of care and disease cure. Fortunately, such procedural trends are already well under way [71].

\section{Abbreviations}

$\mathrm{ABC}=$ abatacept; $\mathrm{ANR}=$ anakinra; $\mathrm{DMARD}=$ disease-modifying antirheumatic drug; IL = interleukin; $M T X=$ methotrexate; $R A=$ rheumatoid arthritis; RIX = rituximab; TBC = tuberculosis; TNF = tumour necrosis factor; $\mathrm{TOZ}=$ tocilizumab.

\section{Competing interests}

The authors declare that they have no competing interests.

Published: 24 August 2010

\section{References}

1. Wollenhaupt J, Alten R, Backhaus M, Baerwald C, Braun J, Burkhardt H, Gaubitz M, Gromnica-Ihle E, Kellner H, Kuipers J, Lorenz H-M, Manger B, Müller-Ladner U, Nüßlein HG, Pott H-G, Rubbert-Roth A, Schneider M, Specker C, Tony H-P, Krüger K: Recommendations for the treatment of rheumatoid arthritis. Results from a German consensus conference: update 2009. Akt Rheumatol 2009, 34:234-239.

2. Smolen JS, Aletaha D, Biilsma JW, Breedveld FC, Boumpas D, Burmester G, Combe B, Cutolo M, de Wit M, Dougados M, Emery P, Gibofsky A, GomezReino JJ, Haraoui B, Kalden J, Keystone EC, Kvien TK, Mclnnes I, Martin-Mola E, Montecucco C, Schoels M, van der Heijde D; T2T Expert Committee: Treating rheumatoid arthritis to target: recommendations of an international task force. Ann Rheum Dis 2010, 69:631-637. 
3. Rodnan GP, Benedek TG: The early history of antirheumatic drugs. Arthritis Rheum 1970, 13:145-165.

4. Andreas K, Haupl T, Lubke C, Ringe J, Morawietz L, Wachtel A, Sittinger M, Kaps $C$ : Antirheumatic drug response signatures in human chondrocytes: potential molecular targets to stimulate cartilage regeneration. Arthritis Res Ther 2009, 11:R15.

5. Molenaar ET, Voskuyl AE, Dinant HJ, Bezemer PD, Boers M, Dijkmans BA: Progression of radiologic damage in patients with rheumatoid arthritis in clinical remission. Arthritis Rheum 2004, 50:36-42.

6. Gladman DD: Established criteria for disease controlling drugs in ankylosing spondylitis. Ann Rheum Dis 2003, 62:793-794.

7. van der Helm-van Mil AH, le Cessie S, van Dongen H, Breedveld FC, Toes RE, Huizinga TW: A prediction rule for disease outcome in patients with recent-onset undifferentiated arthritis: how to guide individual treatment decisions. Arthritis Rheum 2007, 56:433-440.

8. Furst DE, Keystone EC, Fleischmann R, Mease P, Breedveld FC, Smolen JS, Kalden JR, Braun J, Bresnihan B, Burmester GR, De Benedetti F, Dörner T, Emery P, Gibofsky A, Kavanaugh A, Kirkham B, Schiff MH, Sieper J, Singer N, Van Riel PL, Weinblatt ME, Weisman MH, Winthrop K: Updated consensus statement on biological agents for the treatment of rheumatic diseases, 2009. Ann Rheum Dis 2010, 69 Suppl 1:i2-29.

9. van de Putte LB, Atkins C, Malaise M, Sany J, Russell AS, van Riel PL, Settas L, Bijlsma JW, Todesco S, Dougados M, Nash P, Emery P, Walter N, Kaul M, Fischkoff S, Kupper H: Efficacy and safety of adalimumab as monotherapy in patients with rheumatoid arthritis for whom previous disease modifying antirheumatic drug treatment has failed. Ann Rheum Dis 2004, 63:508-516.

10. Breedveld FC, Weisman MH, Kavanaugh AF, Cohen SB, Pavelka K, van Vollenhoven R, Sharp J, Perez JL, Spencer-Green GT: The PREMIER study: a multicenter, randomized, double-blind clinical trial of combination therapy with adalimumab plus methotrexate versus methotrexate alone or adalimumab alone in patients with early, aggressive rheumatoid arthritis who had not had previous methotrexate treatment. Arthritis Rheum 2006, 54:26-37.

11. Klareskog L, van der Heijde D, de Jager JP, Gough A, Kalden J, Malaise M, Martín Mola E, Pavelka K, Sany J, Settas L, Wajdula J, Pedersen R, Fatenejad S, Sanda M; TEMPO (Trial of Etanercept and Methotrexate with Radiographic Patient Outcomes) study investigators: Therapeutic effect of the combination of etanercept and methotrexate compared with each treatment alone in patients with rheumatoid arthritis: double-blind randomised controlled trial. Lancet 2004, 363:675-681.

12. van Vollenhoven RF, Ernestam S, Geborek P, Petersson IF, Cöster L, Waltbrand E, Zickert A, Theander J, Thörner A, Hellström H, Teleman A, Dackhammar C, Akre F, Forslind K, Ljung L, Oding R, Chatzidionysiou A, Wörnert M, Bratt J: Addition of infliximab compared with addition of sulfasalazine and hydroxychloroquine to methotrexate in patients with early rheumatoid arthritis (Swefot trial): 1-year results of a randomised trial. Lancet 2009, 374:459-466.

13. van den Bemt BJ, den Broeder AA, Snijders GF, Hekster YA, van Riel PL, Benraad B, Wolbink GJ, van den Hoogen FH: Sustained effect after lowering high-dose infliximab in patients with rheumatoid arthritis: a prospective dose titration study. Ann Rheum Dis 2008, 67:1697-1701.

14. Smolen JS, Kay J, Doyle MK, Landewé R, Matteson EL, Wollenhaupt J, Gaylis N, Murphy FT, Neal JS, Zhou Y, Visvanathan S, Hsia EC, Rahman MU; GO-AFTER study investigators: Golimumab in patients with active rheumatoid arthritis after treatment with tumour necrosis factor alpha inhibitors (GO-AFTER study): a multicentre, randomised, double-blind, placebocontrolled, phase III trial. Lancet 2009, 374:210-221.

15. Keystone E: Recent concepts in the inhibition of radiographic progression with biologics. Curr Opin Rheumatol 2009, 21:231-237.

16. Furst DE, Wallis R, Broder M, Beenhouwer DO: Tumor necrosis factor antagonists: different kinetics and/or mechanisms of action may explain differences in the risk for developing granulomatous infection. Semin Arthritis Rheum 2006, 36:159-167.

17. Winthrop KL, Yamashita S, Beekmann SE, Polgreen PM: Mycobacterial and other serious infections in patients receiving anti-tumor necrosis factor and other newly approved biologic therapies: case finding through the Emerging Infections Network. Clin Infect Dis 2008, 46:1738-1740.

18. Gomez-Reino JJ, Carmona L, Angel Descalzo M: Risk of tuberculosis in patients treated with tumor necrosis factor antagonists due to incomplete prevention of reactivation of latent infection. Arthritis Rheum 2007,
$57: 756-761$.

19. Soborg B, Ruhwald M, Hetland ML, Jacobsen S, Andersen AB, Milman N, Thomsen VO, Jensen DV, Koch A, Wohlfahrt J, Ravn P: Comparison of screening procedures for Mycobacterium tuberculosis infection among patients with inflammatory diseases. J Rheumatol 2009, 36:1 876-1884.

20. Wallis RS, Broder MS, Wong JY, Hanson ME, Beenhouwer DO: Granulomatous infectious diseases associated with tumor necrosis factor antagonists. Clin Infect Dis 2004, 38:1261-1265.

21. Slifman NR, Gershon SK, Lee JH, Edwards ET, Braun MM: Listeria monocytogenes infection as a complication of treatment with tumor necrosis factor alpha-neutralizing agents. Arthritis Rheum 2003, 48:319-324.

22. Dweik M, Baethge BA, Duarte AG: Coccidioidomycosis pneumonia in a nonendemic area associated with infliximab. South Med J 2007, 100:517-518.

23. Lee JH, Slifman NR, Gershon SK, Edwards ET, Schwieterman WD, Siegel JN, Wise RP, Brown SL, Udall JN, Jr., Braun MM: Life-threatening histoplasmosis complicating immunotherapy with tumor necrosis factor alpha antagonists infliximab and etanercept. Arthritis Rheum 2002, 46:2565-2570.

24. Favalli EG, Desiati F, Atzeni F, Sarzi-Puttini P, Caporali R, Pallavicini FB, Gorla R, Filippini M, Marchesoni A: Serious infections during anti-TNFalpha treatment in rheumatoid arthritis patients. Autoimmun Rev 2009, 8:266-273.

25. Genovese MC, Cohen S, Moreland L, Lium D, Robbins S, Newmark R, Bekker P. Combination therapy with etanercept and anakinra in the treatment of patients with rheumatoid arthritis who have been treated unsuccessfully with methotrexate. Arthritis Rheum 2004, 50:1412-1419.

26. Weinblatt M, Schiff M, Goldman A, Kremer J, Luggen M, Li T, Chen D, Becker $J C$ : Selective costimulation modulation using abatacept in patients with active rheumatoid arthritis while receiving etanercept: a randomised clinical trial. Ann Rheum Dis 2007, 66:228-234

27. Cansu DU, Kalifoglu T, Korkmaz C: Short-term course of chronic hepatitis B and $C$ under treatment with etanercept associated with different disease modifying antirheumatic drugs without antiviral prophylaxis. J Rheumatol 2008, 35:421-424.

28. Kaur PP, Chan VC, Berney SN: Histological evaluation of liver in two rheumatoid arthritis patients with chronic hepatitis $B$ and $C$ treated with TNF-alpha blockade: case reports. Clin Rheumatol 2008, 27:1069-1071.

29. Kapetanovic MC, Saxne T, Nilsson JA, Geborek P: Influenza vaccination as model for testing immune modulation induced by anti-TNF and methotrexate therapy in rheumatoid arthritis patients. Rheumatology (Oxford) 2007, 46:608-611.

30. Geborek P, Bladstrom A, Turesson C, Gulfe A, Petersson IF, Saxne T, Olsson H, Jacobsson LT: Tumour necrosis factor blockers do not increase overall tumour risk in patients with rheumatoid arthritis, but may be associated with an increased risk of lymphomas. Ann Rheum Dis 2005, 64:699-703.

31. Askling J, Baecklund E, Granath F, Geborek P, Fored M, Backlin C, Bertilsson L, Cöster L, Jacobsson LT, Lindblad S, Lysholm J, Rantapää-Dahlqvist S, Saxne T, van Vollenhoven R, Klareskog L, Feltelius N: Anti-tumour necrosis factor therapy in rheumatoid arthritis and risk of malignant lymphomas: relative risks and time trends in the Swedish Biologics Register. Ann Rheum Dis 2009, 68:648-653.

32. Listing J, Strangfeld A, Kekow J, Schneider M, Kapelle A, Wassenberg S, Zink A: Does tumor necrosis factor alpha inhibition promote or prevent heart failure in patients with rheumatoid arthritis? Arthritis Rheum 2008, 58:667-677.

33. Popa $C$, van Tits LJ, Barrera P, Lemmers $H L$, van den Hoogen FH, van Riel PL, Radstake TR, Netea MG, Roest M, Stalenhoef AF: Anti-inflammatory therapy with tumour necrosis factor alpha inhibitors improves high-density lipoprotein cholesterol antioxidative capacity in rheumatoid arthritis patients. Ann Rheum Dis 2009, 68:868-872.

34. Ostor AJ, Chilvers ER, Somerville MF, Lim AY, Lane SE, Crisp AJ, Scott DG: Pulmonary complications of infliximab therapy in patients with rheumatoid arthritis. J Rheumatol 2006, 33:622-628.

35. Hamon MA, Nicolas G, Deviere F, Letournel F, Dubas F: [Demyelinating neuropathy during anti-TNF alpha treatment with a review of the literature]. Rev Neurol (Paris) 2007, 163:1232-1235.

36. Gonnet-Gracia C, Barnetche T, Richez C, Blanco P, Dehais J, Schaeverbeke T: Anti-nuclear antibodies, anti-DNA and C4 complement evolution in rheumatoid arthritis and ankylosing spondylitis treated with TNF-alpha blockers. Clin Exp Rheumatol 2008, 26:401-407.

37. Costa MF, Said NR, Zimmermann B: Drug-induced lupus due to anti-tumor necrosis factor alpha agents. Semin Arthritis Rheum 2008, 37:381-387. 
38. Fleischmann RM, lqbal I, Stern RL: Considerations with the use of biological therapy in the treatment of rheumatoid arthritis. Expert Opin Drug Saf 2004, 3:391-403.

39. Berthelot JM, De Bandt M, Goupille P, Solau-Gervais E, Lioté F, Goeb V, Azaïs I, Martin A, Pallot-Prades B, Maugars Y, Mariette X; CRI (Club Rhumatismes et Inflammation): Exposition to anti-TNF drugs during pregnancy: outcome of 15 cases and review of the literature. Joint Bone Spine 2009, 76:28-34.

40. Emery P, Fleischmann R, Filipowicz-Sosnowska A, Schechtman J, Szczepanski L, Kavanaugh A, Racewicz AJ, van Vollenhoven RF, Li NF, Agarwal S, Hessey EW, Shaw TM; DANCER Study Group: The efficacy and safety of rituximab in patients with active rheumatoid arthritis despite methotrexate treatment: results of a phase IIB randomized, double-blind, placebo-controlled, doseranging trial. Arthritis Rheum 2006, 54:1390-1400.

41. Higashida J, Wun T, Schmidt S, Naguwa SM, Tuscano JM: Safety and efficacy of rituximab in patients with rheumatoid arthritis refractory to disease modifying antirheumatic drugs and anti-tumor necrosis factor-alpha treatment. J Rheumatol 2005, 32:2109-2115.

42. Keystone E, Emery P, Peterfy CG, Tak PP, Cohen S, Genovese MC, Dougados M, Burmester GR, Greenwald M, Kvien TK, Williams S, Hagerty D, Cravets MW, Shaw T: Rituximab inhibits structural joint damage in patients with rheumatoid arthritis with an inadequate response to tumour necrosis factor inhibitor therapies. Ann Rheum Dis 2009, 68:216-221.

43. Edwards JC, Szczepanski L, Szechinski J, Filipowicz-Sosnowska A, Emery P, Close DR, Stevens RM, Shaw T: Efficacy of B-cell-targeted therapy with rituximab in patients with rheumatoid arthritis. N Engl J Med 2004, 350:2572-2581.

44. Cohen SB, Emery P, Greenwald MW, Dougados M, Furie RA, Genovese MC, Keystone EC, Loveless JE, Burmester GR, Cravets MW, Hessey EW, Shaw T, Totoritis MC; REFLEX Trial Group: Rituximab for rheumatoid arthritis refractory to anti-tumor necrosis factor therapy: Results of a multicenter, randomized, double-blind, placebo-controlled, phase III trial evaluating primary efficacy and safety at twenty-four weeks. Arthritis Rheum 2006, 54:2793-2806.

45. Assous N, Gossec L, Dieude P, Meyer O, Dougados M, Kahan A, Allanore Y: Rituximab therapy in rheumatoid arthritis in daily practice. $J$ Rheumatol 2008, 35:31-34.

46. Quartuccio L, Fabris M, Salvin S, Atzeni F, Saracco M, Benucci M, Cimmino M, Morassi P, Masolini P, Pellerito R, Cutolo M, Puttini PS, De Vita S: Rheumatoid factor positivity rather than anti-CCP positivity, a lower disability and a lower number of anti-TNF agents failed are associated with response to rituximab in rheumatoid arthritis. Rheumatology (Oxford) 2009, 48:1557-1559.

47. Keystone E, Fleischmann R, Emery P, Furst DE, van Vollenhoven R, Bathon J, Dougados M, Baldassare A, Ferraccioli G, Chubick A, Udell J, Cravets MW, Agarwal S, Cooper S, Magrini F: Safety and efficacy of additional courses of rituximab in patients with active rheumatoid arthritis: an open-label extension analysis. Arthritis Rheum 2007, 56:3896-3908.

48. Thurlings RM, Vos K, Gerlag DM, Tak PP: Disease activity-guided rituximab therapy in rheumatoid arthritis: the effects of re-treatment in initial nonresponders versus initial responders. Arthritis Rheum 2008, 58:3657-3664.

49. Looney RJ, Srinivasan R, Calabrese LH: The effects of rituximab on immunocompetency in patients with autoimmune disease. Arthritis Rheum 2008, 58:5-14

50. Salliot C, Dougados M, Gossec L: Risk of serious infections during rituximab, abatacept and anakinra treatments for rheumatoid arthritis: metaanalyses of randomised placebo-controlled trials. Ann Rheum Dis 2009, 68:25-32.

51. Thurlings RM, Vos K, Wijbrandts CA, Zwinderman AH, Gerlag DM, Tak PP Synovial tissue response to rituximab: mechanism of action and identification of biomarkers of response. Ann Rheum Dis 2008, 67:917-925.

52. Fleischmann RM: Progressive multifocal leukoencephalopathy following rituximab treatment in a patient with rheumatoid arthritis. Arthritis Rheum 2009, 60:3225-3228.

53. Dass S, Vital EM, Emery P: Development of psoriasis after B cell depletion with rituximab. Arthritis Rheum 2007, 56:2715-2718.

54. Kremer JM, Genant HK, Moreland LW, Russell AS, Emery P, Abud-Mendoza C, Szechinski J, LiT, Ge Z, Becker JC, Westhovens R: Effects of abatacept in patients with methotrexate-resistant active rheumatoid arthritis: a randomized trial. Ann Intern Med 2006, 144:865-876.

55. Genovese MC, Becker JC, Schiff M, Luggen M, Sherrer Y, Kremer J, Birbara C,
Box J, Natarajan K, Nuamah I, Li T, Aranda R, Hagerty DT, Dougados M: Abatacept for rheumatoid arthritis refractory to tumor necrosis factor alpha inhibition. N Eng/ J Med 2005, 353:1114-1123.

56. Schiff M, Pritchard C, Huffstutter JE, Rodriguez-Valverde V, Durez P, Zhou X, L T, Bahrt K, Kelly S, Le Bars M, Genovese MC: The 6-month safety and efficacy of abatacept in patients with rheumatoid arthritis who underwent $a$ washout after anti-tumour necrosis factor therapy or were directly switched to abatacept: the ARRIVE trial. Ann Rheum Dis 2009, 68:1708-1714

57. Kremer JM, Genant HK, Moreland LW, Russell AS, Emery P, Abud-Mendoza C, Szechiński J, Li T, Teng J, Becker JC, Westhovens R: Results of a two-year followup study of patients with rheumatoid arthritis who received a combination of abatacept and methotrexate. Arthritis Rheum 2008, 58:953-963.

58. Schiff M, Keiserman M, Codding C, Songcharoen S, Berman A, Nayiager S, Saldate C, Li T, Aranda R, Becker JC, Lin C, Cornet PL, Dougados M: Efficacy and safety of abatacept or infliximab vs placebo in ATTEST: a phase III, multi-centre, randomised, double-blind, placebo-controlled study in patients with rheumatoid arthritis and an inadequate response to methotrexate. Ann Rheum Dis 2008, 67:1096-1103.

59. Weinblatt M, Combe B, Covucci A, Aranda R, Becker JC, Keystone E: Safety of the selective costimulation modulator abatacept in rheumatoid arthritis patients receiving background biologic and nonbiologic diseasemodifying antirheumatic drugs: A one-year randomized, placebocontrolled study. Arthritis Rheum 2006, 54:2807-2816.

60. Bresnihan B, Newmark R, Robbins S, Genant HK: Effects of anakinra monotherapy on joint damage in patients with rheumatoid arthritis. Extension of a 24-week randomized, placebo-controlled trial. J Rheumatol 2004, 31:1103-1111.

61. Karanikolas G, Charalambopoulos D, Vaiopoulos G, Andrianakos A, Rapti A, Karras D, Kaskani E, Sfikakis PP: Adjunctive anakinra in patients with active rheumatoid arthritis despite methotrexate, or leflunomide, or cyclosporinA monotherapy: a 48-week, comparative, prospective study. Rheumatology (Oxford) 2008, 47:1384-1388

62. Fleischmann R, Stern R, labal I: Anakinra: an inhibitor of IL-1 for the treatment of rheumatoid arthritis. Expert Opin Biol Ther 2004, 4:1333-1344.

63. Furst DE: The risk of infections with biologic therapies for rheumatoid arthritis. Semin Arthritis Rheum 2008, 39:327-346.

64. Mertens M, Singh JA: Anakinra for rheumatoid arthritis: a systematic review. J Rheumatol 2009, 36:1118-1125.

65. Nam JL, Winthrop KL, van Vollenhoven RF, Pavelka K, Valesini G, Hensor EM, Worthy G, Landewé R, Smolen JS, Emery P, Buch MH: Current evidence for the management of rheumatoid arthritis with biological diseasemodifying antirheumatic drugs: a systematic literature review informing the EULAR recommendations for the management of RA. Ann Rheum Dis 2010, 69:976-986.

66. Smolen JS, Beaulieu A, Rubbert-Roth A, Ramos-Remus C, Rovensky J, Alecock E, Woodworth T, Alten R: Effect of interleukin- 6 receptor inhibition with tocilizumab in patients with rheumatoid arthritis (OPTION study): a double-blind, placebo-controlled, randomised trial. Lancet 2008 371:987-997.

67. Emery P, Keystone E, Tony HP, Cantagrel A, van Vollenhoven R, Sanchez A, Alecock E, Lee J, Kremer J: IL-6 receptor inhibition with tocilizumab improves treatment outcomes in patients with rheumatoid arthritis refractory to anti-tumour necrosis factor biologicals: results from a 24-week multicentre randomised placebo-controlled trial. Ann Rheum Dis 2008, 67:1516-1523.

68. Nishimoto N, Miyasaka N, Yamamoto K, Kawai S, Takeuchi T, Azuma J, Kishimoto T: Study of active controlled tocilizumab monotherapy for rheumatoid arthritis patients with an inadequate response to methotrexate (SATORI): significant reduction in disease activity and serum vascular endothelial growth factor by IL-6 receptor inhibition therapy. Mod Rheumatol 2009, 19:12-19.

69. Nishimoto N, Miyasaka N, Yamamoto K, Kawai S, Takeuchi T, Azuma J: Longterm safety and efficacy of tocilizumab, an anti-IL-6 receptor monoclonal antibody, in monotherapy, in patients with rheumatoid arthritis (the STREAM study): evidence of safety and efficacy in a 5-year extension study. Ann Rheum Dis 2009, 68:1580-1584.

70. Genovese MC, MCKay JD, Nasonov EL, Mysler EF, da Silva NA, Alecock E, Woodworth T, Gomez-Reino JJ: Interleukin-6 receptor inhibition with tocilizumab reduces disease activity in rheumatoid arthritis with inadequate response to disease-modifying antirheumatic drugs: the 
tocilizumab in combination with traditional disease-modifying antirheumatic drug therapy study. Arthritis Rheum 2008, 58:2968-2980

71. Pham T, Claudepierre P, Constantin A, Fautrel B, Gossec L, Gottenberg JE, Goupille P, Hachulla E, Masson C, Morel J, Saraux A, Schaeverbeke T, Wendling D, Mariette X, Sibilia J: Abatacept therapy and safety management. Joint Bone Spine 2009, 76 Suppl 1:S3-S55. doi:10.1186/ar3102

Cite this article as: Geyer M, Müller-Ladner U: Rationale of using different biological therapies in rheumatoid arthritis. Arthritis Research \& Therapy 2010, $12: 214$ 